\title{
A CORTE CONSTITUCIONAL INTERNACIONAL NO ATUAL CONTEXTO DE CONSTITUCIONALISMO SOCIAL: CONTRIBUIÇÕES NA CONSTRUÇÃO DA DEMOCRACIA CONTÍNUA
}

\author{
Bernardo Leandro Carvalho Costa ${ }^{1}$
}

Leonel Severo Rocha ${ }^{2}$

Resumo: o presente trabalho tem como objetivos contextualizar o projeto de criação de uma Corte Constitucional Internacional no atual cenário de constitucionalismo social e verificar em que medida a criação de uma nova estrutura jurisdicional como essa contribuiria para a resolução de problemas envolvendo relações de poder a nível global. Para tal, utiliza-se da metodologia sistêmica, com ênfase nos recentes estudos em Sociologia das Constituições, para observar a conveniência e o enquadramento da Corte Constitucional Internacional como possível contribuição no controle de processos para a manutenção do Estado de Direito e fortalecimento da democracia contínua ao redor do mundo.

Palavras-chave: Corte Constitucional Internacional; Constitucionalismo Social; Sociologia das Constituições Teoria dos Sistemas Sociais; Democracia contínua;

\begin{abstract}
International Constitutional Court in the current scenario of social constitutionalism and to verify to what extent the creation of a new jurisdictional structure like this would contribute to the resolution of problems involving power relations at world. For this purpose, the systemic methodology is used, with emphasis in the recent studies in Sociology of the Constitutions, to observe the convenience and the framework of the International Constitutional Court as a possible contribution in the control
\end{abstract}

\footnotetext{
1 Doutorando em Direito Público pelo Programa de Pós-Graduação em Direito da Unisinos. Bolsista Capes/PROEX. Membro de grupo de pesquisa Teoria do Direito (CNPq). Possui experiência nas áreas de Teoria Constitucional e Sociologia Jurídica, atuando principalmente nos seguintes temas: Constitucionalismo Social, Sociologia das Constituições e Teoria dos Sistemas Sociais. bernardoleandro@ me.com.

${ }^{2}$ Doutor pela Ecole des Hautes Etudes en Sciences Sociales de Paris. Realizou Pós-doutorado em Sociologia do Direito pela Universita degli Studi di Lecce - Itália. Professor do Programa de Pós-Graduação em Direito da Unisinos. Possui experiência na área de Direito, com ênfase em Teoria Geral do Direito, trabalhando principalmente os seguintes temas: Teoria dos Sistemas Sociais, Democracia e Teoria do Direito. leonel@unisinos.br.
}

Rev. Brasileira de Teoria Constitucional | e-ISSN: 2525-961X| Goiânia| v. 5 | n. 1 | p. 1 - 20 | Jan/Jun. 2019 
of processes for the maintenance of the Rule of Law and strengthening of continuous democracy worldwide.

Keywords: International Constitutional Court; Social Constitutionalism; Sociology of Constitutions Social System's theory; Continuous democracy;

\section{INTRODUÇÃO}

Em um cenário de repetidas eleições contestadas na Tunísia, com a reeleição contínua do então presidente Zine El Abidine Ben Ali, M. Makouzi, político opositor, pleiteou a deposição de um regime que considerou como ditatorial em seu país. Na denúncia, realizada junto à Organização das Nações Unidas (ONU), Makouzi, que depois de tornaria presidente da Tunísia, evidenciou a falta de acesso que certos países possuem em relação aos mecanismos de proteção aos direitos humanos existentes no Direito Internacional no tocante a fatos como esse, envolvendo eleições, que envolvia diretamente a manutenção de processos democráticos ao redor do mundo.

No ato, na presença de renomados intelectuais, surgiu a proposta de criação de uma Corte Constitucional Internacional, com vistas a preencher esse vácuo de ausência de mecanismos efetivos para a contestação de violações à democracia.

Partindo dessa perspectiva, observando as questões denunciadas acerca do caso tunisiano por M. Makouzi, o problema levantado no presente trabalho refere-se, por um lado, à ausência de acesso de determinados países em relação aos mecanismos de proteção aos direitos humanos existentes no Direito Internacional para o controle de processos eleitorais ao redor do mundo. Por outro lado, como possível resposta à problemática levantada, busca constatar se a criação da Corte Constitucional Internacional pode contribuir para a solução desse impasse, levando-se em conta, nessa perspectiva, a existência de diversos estudos no âmbito da Sociologia das Constituições acerca da globalização do Direito Constitucional.

Tendo como temas centrais a proposta de criação de uma Corte Constitucional Internacional e o atual ambiente do constitucionalismo na globalização, o presente trabalho tem como objetivos demonstrar a diferença entre o referido projeto e o atual cenário em matéria de direito internacional dos direitos humanos e analisar essa temática na perspectiva

Rev. Brasileira de Teoria Constitucional | e-ISSN: 2525-961X| Goiânia| v. 5 | n. 1 | p. 1 - 20 | Jan/Jun. 2019 


\section{A CORTE CONSTITUCIONAL INTERNACIONAL NO ATUAL CONTEXTO DE CONSTITUCIONALISMO SOCIAL: CONTRIBUIÇÕES NA CONSTRUÇÃO DA DEMOCRACIA CONTÍNUA}

de um Direito Constitucional globalizado, verificando em que medida a criação de uma Corte contribuiria para a resolução de problemas constitucionais a nível global.

Justifica-se tal proposta na medida em que já existem mecanismos de proteção aos direitos humanos a nível internacional, ao mesmo tempo em que surge a proposta de criação de uma Corte. Todavia, há uma dificuldade em se evidenciar as diferenças entre o que já existe e o que é proposto no projeto de criação dessa nova instância jurisdicional internacional. Ademais, verifica-se a ausência de seu enquadramento no atual cenário de globalização do Direito Constitucional.

Nesse sentido, busca-se, inicialmente, fazer uma construção histórica acerca do constitucionalismo, destacando o contexto de seu surgimento vinculado a Constituições escritas no final do século XVIII. Na sequência, demonstrar-se-á a continuidade de perspectiva muito semelhante nos debates constitucionais nos séculos subsequentes, até o final do século XX, quando o fenômeno da globalização altera sobremaneira a perspectiva de regulação das relações do poder entre os cidadãos e o Estado, alçado a um plano transnacional.

A partir dessa constatação de ruptura entre a tradição perspectiva de um constitucionalismo estatal, vinculado a Constituições escritas e de uma nova etapa em que os Estados estão inseridos no fenômeno da globalização, demonstra-se o surgimento de um ramo de estudos apto ao enfrentamento dessas questões, a Sociologia das Constituições (THORNHILL, 2011).

Nesse âmbito, como será demonstrado ao longo do trabalho, a exemplo da boa síntese realizada por Febbrajo (2016), há alternativas teóricas para uma adequada observação da evolução do constitucionalismo na globalização, com autores que propõem uma conversação constitucional entre tribunais de diferentes níveis para a solução de problemas comuns (NEVES, 2009), ou ainda, evidenciando que há Constituições transnacionais (THORNHILL, 2016) que perpassam as decisões de diferentes tribunais nacionais em matéria de direitos humanos.

Ao extremo dessa problemática, pode-se dizer, ainda, que há questões que fogem ao âmbito do Direito Público, mas estão envolvidas em temas de Direito Constitucional, a exemplo da fragmentação constitucional dos regimes privados, como destacado por Teubner Rev. Brasileira de Teoria Constitucional | e-ISSN: 2525-961X| Goiânia| v. 5 | n. 1 | p. 1 - 20 | Jan/Jun. 2019 
(2016). A síntese dessas questões forma o que hoje se denomina de Constitucionalismo Social (ROCHA; COSTA, 2018), delineando o conjunto de problemas constitucionais envolvidos no ambiente social, não necessariamente vinculados ao Estado.

O intuito, nessa parte da pesquisa, é contextualizar o surgimento do projeto da Corte Constitucional Internacional na atual quadra do constitucionalismo, demonstrando que referida proposta está envolvida em um embate entre a possibilidade de reforçar propostas que já existem no âmbito da Sociologia das Constituições para o enfrentamento de problemas constitucionais de natureza transnacional, e a necessidade - ou não- de se criar uma Corte específica para tal.

Como metodologia será utilizada a sistêmica, com fundamento da Teoria dos Sistemas Sociais (LUHMANN, 2016), bem como a técnica de pesquisa de documentação indireta, com revisão de bibliografia nacional e estrangeira.

Nesse âmbito, a Sociologia das Constituições (THORNHILL, 2011) será fundamental para a análise da Corte Constitucional Internacional no atual cenário de globalização do Direito Constitucional, evidenciando as diferenças entre perspectivas de um constitucionalismo voltado à existência de uma Constituição escrita vinculada a determinado Estado e de problemáticas atuais da globalização, demonstrando a necessidade de resolução de problemas constitucionais comuns a nível global.

\section{O CONSTITUCIONALISMO ENTRE O NACIONAL E O TRANSNACIONAL}

O constitucionalismo surge como técnica jurídico-constitucional de limitação do poder político por meio de uma constituição escrita (BOBBIO, 1997) na onda dos eventos revolucionários no final do século XVIII. Nesse sentido, a França possui destaque em influência para os demais países.

Nesse contexto, Carré de Malberg (1948) teoriza o Direito Constitucional como um ramo do Direito Público, cujo papel seria o de regular o exercício do poder do Estado sobre os cidadãos a ele pertencentes nos limites de um território. Há uma conexão estrita entre a necessidade de um documento escrito, portanto, e de elementos caracterizados da Teoria Geral do Estado (povo, território e soberania).

Rev. Brasileira de Teoria Constitucional | e-ISSN: 2525-961X| Goiânia| v. 5 | n. 1 | p. 1 - 20 | Jan/Jun. 2019 


\section{A CORTE CONSTITUCIONAL INTERNACIONAL NO ATUAL CONTEXTO DE CONSTITUCIONALISMO SOCIAL: CONTRIBUIÇÕES NA CONSTRUÇÃO DA DEMOCRACIA CONTÍNUA}

Em um território, o Estado exerce seu poder sobre o povo a ele vinculado:

[...] uma comunidade não é apta a formar um Estado se não possui um solo, uma superfície de terra sobre a qual pode afirmar-se como dona de si mesma e independente, é dizer, sobre a qual possa, ao mesmo tempo, impor seu próprio poder e rechaçar a intervenção de poderes alheios. (MALBERG, 1948, p. 23). ${ }^{3}$ (tradução nossa).

A evidência da necessidade de documentos escritos é destacada na própria Declaração dos Direitos do Homem e do Cidadão, que, em ser artigo 16, afirma o seguinte: "Qualquer sociedade em que não esteja assegurada a garantia dos direitos, nem estabelecida a separação dos poderes não tem Constituição (artigo 16).” (DECLARAÇÃO, 2018).

Na Alemanha, Jellinek (2000), um grande teórico do Estado, é quem afirma a importância da França na origem dessa perspectiva de constitucionalismo. Em sentido semelhante, afirma que a função do Direito Constitucional é regular o exercício do imperium estatal sobre os indivíduos que a ele pertencem no âmbito de determinado território.

Está se falando, nessa época de surgimento, de um constitucionalismo clássico, cuja influência que parte da França se espalha pela Europa, muito em razão, posteriormente, das conquistas realizadas por Napoleão Bonaparte. Em termos de períodos da história constitucional, evidenciando o Direito Comparado, Di Ruffia (1993, p.93) afirma que:

Em consequência, pode-se demonstrar que a etapa do "constitucionalismo clássico" se desenvolveu no mundo moderno entre 1787 e o fim da primeira Guerra Mundial de acordo com cinco "ciclos sucessivos", por meio de uma série de conceitos e realizações que se percebem facilmente em sua progressividade linear, incluindo as seguintes Constituições: revoluções do século XVIII (1789-1799), napoleônicas (1799-1815), da Restauração (1815-1830), liberais (1830-1848) e democráticas (1848-1918), entre elas várias de caráter federal (1848-1874); porém a partir de então as Constituições tem se orientado em direções diversas e contrastantes. (tradução nossa).

Esse pano de fundo da origem do Direito Constitucional destaca a necessidade de se ter Constituições escritas com elementos aptos a controlar o exercício do poder do Estado.

\footnotetext{
${ }^{3}$ No original: "[...] una comunidad no es apta a formar un Estado sino mientras posea un suelo, una superficie de tierra sobre la cual pueda afirmarse como dueña de sí misma e independiente, es decir, sobre la cual pueda, al mismo tiempo, imponer su propia potestad y rechazar la intervención de toda potestad ajena."
}

Rev. Brasileira de Teoria Constitucional | e-ISSN: 2525-961X| Goiânia| v. 5 | n. 1 | p. 1 - 20 | Jan/Jun. 2019 
Segundo o exemplo que consta na Declaração dos Direitos do Homem e do Cidadão (DECLARAÇÃO, 2018), uma análise constitucional seria baseada, nessa perspectiva, na demonstração de que determinada Constituição que contivesse a separação de poderes e a garantia de direitos seria uma boa Constituição.

Tal ponto de observação avançou o século XX sem se desvencilhar da necessidade de se ter Constituições escritas. Do mesmo modo, a imprescindibilidade de vincular os documentos constitucionais aos elementos caracterizadores do Estado foi mantida.

No relevante debate travado por Kelsen (2003) e Schmitt (2007) ao longo do século XX, há uma divergência no que tange a quem deveria ficar a guarda da Constituição.

Para Kelsen (2003, p. 131), a Constituição: “[...] é a norma que rege e elabora as leis, das normas gerais para cuja execução se exerce a atividade dos organismos estatais, dos tribunais e das autoridades administrativas." O Controle dessa norma que rege a elaboração das demais normas deveria ser exercido por um órgão diferente e independente do parlamento.

Schmitt (2007, p. 121), por sua vez, afirma que:

Conforme o direito positivo da Constituição de Weimar, a posição do presidente do Reich, eleito pela totalidade do povo, só pode ser construída com a ajuda de uma teoria mais desenvolvida de um poder neutro intermediário, regulador e preservador. O presidente do Reich está munido de poderes que o tornam independentes dos órgãos legislativos, embora esteja vinculado, simultaneamente, à referenda dos ministros independentes da confiança do parlamento.

Assim, em que pese os acirrados debates constitucionais entre Kelsen (2003) e Schmitt (2007), limitados acerca de quem deveria ser o guardião da Constituição, os demais elementos da discussão mantiveram as perspectivas já elencadas no surgimento do constitucionalismo, destacando a evidência de um documento constitucional escrito vinculado ao território de determinado Estado.

No final do século XX, todavia, com o impulso do fenômeno da globalização (ZOLO, 2010), cuja maior consequência foi a disseminação das relações de poder para além dos Estados nacionais, o Direito Constitucional passa a conviver com problemáticas que o tocam,

Rev. Brasileira de Teoria Constitucional | e-ISSN: 2525-961X| Goiânia| v. 5 | n. 1 | p. 1 - 20 | Jan/Jun. 2019 


\section{A CORTE CONSTITUCIONAL INTERNACIONAL NO ATUAL CONTEXTO DE CONSTITUCIONALISMO SOCIAL: CONTRIBUIÇÕES NA CONSTRUÇÃO DA DEMOCRACIA CONTÍNUA}

mas que estão alçadas ao plano global. As tradicionais caracterizações, considerando a necessidade de uma Constituição escrita vinculada aos elementos do Estado, a exemplo de Malberg (1948) e Jellinek (2000), ou ainda, do que consta na Declaração dos Direitos do Homem e do Cidadão (DECLARAÇÃO, 2018) são insuficientes para a observação do atual desafio em que o constitucionalismo está inserido.

Como visto, nos teóricos do século XX, a exemplo de Kelsen (2003) e Schmitt (2007), até mesmo por limitação temporal, não há considerações acerca dessa possibilidade. O que há em Kelsen (2003) é uma consideração acerca do Direito Internacional, mas que se limita a um plano de atuação em que não há sanções.

Em suma, no final do século $\mathrm{XX}$, renomados autores passam a evidenciar essa insuficiência do Direito Constitucional. Nesse contexto, enquadram-se os autores do pluralismo jurídico, a exemplo de Bermann (2013), Shaffer (2012) e Tamanaha (2008), que evidenciam o deslocamento do Direito do plano nacional para o transnacional.

No tocante ao Direito Constitucional, a matriz sistêmica de observação destaca-se nessa transição de análise do constitucionalismo. Isso porque a Teoria dos Sistemas Sociais (LUHMANN, 2016) é uma proposta já adaptada ao contexto da globalização.

Nesse sentido, é relevante a transição de José Joaquim Gomes Canotilho, relevante constitucionalista português, de uma perspectiva mais fechada de observação do Direito Constitucional, característica se sua obra "Constituição dirigente" (CANOTILHO, 1982) para observações fundadas na matriz sistêmica, evidenciadas a partir de sua obra "Brancosos e interconstitucionalidade" (CANOTILHO, 2008).

Em síntese, Canotilho sai de uma perspectiva fundada na observação da Constituição de Portugal, um documento único e escrito que possuía, segundo o autor, certo dirigismo estatal (CANOTILHO, 1982). Nesse sentido:

O problema central da Constituição dirigente consistia (e consiste) em saber se, através de 'programas', tarefas e directivas constitucionais, se conseguiria uma imediaticidade actuativa e concretizável das normas e princípios constitucionais de forma a acabar com os queixumes constitucionais da 'constituição não cumprida' ou da 'não concretização da constituição. (CANOTILHO, 2008, p. 32). 
Canotilho (2008) afasta-se dessa perspectiva constitucional estrita para observar as relações de Direito Constitucional existentes entre os diferentes países da União Europeia, o que denominou de interconstucionalidade (CANOTILHO, 2008). A partir desse momento, em aspectos comparáveis à perspectiva de fragmentação destacada por outros autores, Canotilho (2008, p. 185) passou a afirmar que:

[...] o direito constitucional é um 'direito de restos. 'Direito do resto do Estado', depois da transferência de competências e atribuições deste, a favor de organizações supranacionais (União Europeia, Mercosul). Direito do resto do 'nacionalismo jurídico', depois das consistentes e persistentes internacionalização e globalização terem reduzido o Estado a um simples 'herói do local'.

Seguindo essa perspectiva nos Estados Unidos, Bruce Ackermann (2007) defendeu a necessária abertura do Direito Constitucional Estadunidense aos influxos da globalização, afastando-se de um modelo provincialista de Constituição para observar a ascensão de um constitucionalismo mundial.

Avançando nessa questão acerca da globalização do Direito Constitucional surgiu um ramo de estudos denominado de Sociologia das Constituições. Calcado nas construções teóricas da Teoria dos Sistemas Sociais de Luhmann (2016), a proposta é de observar as relações entre os sistemas da Política e do Direito para além dos Estados nacionais, na perspectiva de sociedade mundial descrita na construção luhmanniana.

Na teoria de Luhmann (2016), a Constituição não é observada apenas no tocante à existência de um documento único que regula o exercício do poder do Estado dentro de determinado território, mas a partir de relações recíprocas de interdependência entre os sistemas do Direito e da Política. Essa concepção é fundamental para a observação dos atuais problemas constitucionais na globalização. Assim:

A Constituição, portanto, medeia as relações entre os sistemas sociais da Política e do Direito, possibilitando uma observação sistêmica do Direito Constitucional. Essa interpenetração entre os sistemas (acoplamento estrutural)- como já destacado acima- é feita pela Constituição e pode ser observada a partir de um contexto histórico, com o próprio surgimento do Estado, portador desse acoplamento estrutural entre os sistemas da Política e do Direito, cuja condição para tal é a existência de uma Constituição capaz 


\title{
A CORTE CONSTITUCIONAL INTERNACIONAL NO ATUAL CONTEXTO DE CONSTITUCIONALISMO SOCIAL: CONTRIBUIÇÕES NA CONSTRUÇÃO DA DEMOCRACIA \\ CONTÍNUA
}

de permitir que o direito positivo se converta em um meio de conformação política, bem como que o Direito Constitucional possa, nesses termos, se tornar instrumento jurídico para a implantação de uma disciplinarização política. (ROCHA; COSTA, 2018, p. 45).

Essa relevante transição é explicada por Febbrajo (2016) ao evidenciar a necessidade de passagem de observações mais estritas do constitucionalismo, calcadas em uma matriz analítica de observação (ROCHA, 2013), para análises sistêmicas do atual contexto do Direito Constitucional. Nesse sentido, Febbrajo (2016, p. 18):

\begin{abstract}
A imagem tranquilizadora, fornecida pelo positivismo jurídico, de uma constituição posta no vértice das normas do direito é assim corrigida por uma representação policêntrica em que os fatores sociais de diversa natureza desempenham um papel importante ao lado dos fatores jurídicos, e o direito é explicado com e na sociedade, ao invés de somente com o direito.
\end{abstract}

Sendo assim, ao Direito Constitucional, antes voltado à solução de problemas vinculados aos Estados nacionais, surgem novas problemáticas vinculadas à ordem global. Exemplo disso é o próprio contexto de reeleições irregulares seguidas na Tunísia, em afronta ao Estado de Direito e à democracia, denunciadas por M. Makouzi em busca de uma resposta global para o problema.

A partir dessa perspectiva de observação, Chris Thornhill (2016), no âmbito da Sociologia das Constituições (THORNHILL, 2011) afirma que há Constituições Transnacionais formadas em matéria de direitos humanos. Em síntese, desde as Constituições elaboradas após o final da Segunda Guerra Mundial na Europa até os dias atuais, há um rol de direitos comum a vários países. Esse catálogo de direitos é aplicado em tribunais de diferentes níveis:

1- [...] atualmente as sociedades nacionais cada vez mais constroem suas estruturas de inclusão por meio de diferentes processos de formação normativa, localizadas, ambas, entre os territórios nacional e 'extranacional"." 2- [...] a sociedade global como um todo, entre instituições nacionais e processos políticos, também está desenvolvendo uma constituição transnacional. ${ }^{4}$ (THORNHILL, 2016, p. 8). (tradução livre).

\footnotetext{
${ }^{4}$ No original: "1- [...] national societies now increasingly construct their inclusionary structure through many different processes of norm formation, often located between the national and the extra-national domain. 2- [...] global society as a whole, beyond national institutions and political processes, is also developing a distinct transnational constitution."
}

Rev. Brasileira de Teoria Constitucional | e-ISSN: 2525-961X| Goiânia| v. 5 | n. 1 | p. 1 - 20 | Jan/Jun. 2019 
Referido rol de direitos, desenvolvido em processo dialético entre estruturas nacionais e internacionais serviria para o enfrentamento dos atuais problemas constitucionais alçados a nível global.

Perspectiva que se aproxima da de Chris Thornhill (2016) é a de Marcelo Neves (2008) acerca do transconstitucionalismo. Para Neves (2008), que também parte de uma observação sistêmica do Direito Constitucional, a disciplina está atualmente envolvida em problemas de natureza global. O autor exemplifica com a temática do terrorismo e dos crimes ambientais, envolvidos na era da globalização. Pode-se adicionar, ainda, o atual combate à lavagem de dinheiro, crime de natureza transnacional (COSTA, ROCHA, 2018b). Para o enfrentamento de tais questões, propõe o estímulo de um diálogo constitucional entre tribunais de diferentes níveis, o que denomina de Transconstitucionalismo. Assim:

Na construção da norma jurídica e da norma de decisão, cada uma das ordens envolvidas pode considerar como dimensão do seu âmbito normativo elementos do âmbito material relevante originalmente para outra ordem, como também incorporar como dimensão do seu programa normativo partes do programa normativo de outras ordens. Ou seja, partindo simultaneamente dos textos normativos e dos casos comuns, podem ser construídas normas diversas tendo em vista os possíveis processos de concretização que se desenvolverão na ordem colidente ou parceira. (NEVES, 2008, p.127-128).

Como se viu, há uma aproximação entre Thornhill (2016) e Neves (2008) no tocante à existência/necessidade de formação de parâmetros transnacionais de constitucionalismo para o enfrentamento de problemas de natureza global. Há consenso, todavia, em relação à necessidade de adaptação da Teoria Constitucional ao fenômeno da globalização. Nesse ponto, ainda há uma preocupação com fenômenos vinculados ao âmbito do Direito Público. Há, ainda, relevantes autores que destacam a importância de se observar problemas constitucionais que se desenvolvem no âmbito dos regimes privados, a exemplo de Teubner (2016).

Para Teubner (2016), na sociedade mundial (LUHMANN, 2016) há a assunção de funções jurisdicionais por atores que não estão conectados aos sistemas do Direito e da Política, mas a outras esferas do sistema social.

Nesse sentido, afirma Teubner (2003, p. 10) que: "Nos dias atuais de hoje estão se constituindo em "autonomia relativa" diante do Estado-nação, bem como diante da política 


\section{A CORTE CONSTITUCIONAL INTERNACIONAL NO ATUAL CONTEXTO DE CONSTITUCIONALISMO SOCIAL: CONTRIBUIÇÕES NA CONSTRUÇÃO DA DEMOCRACIA CONTÍNUA}

internacional, setores distintos da sociedade mundial que produzem a partir de si mesmos ordenamentos jurídicos globais sui generis."

Assim, a título de exemplo, como demonstra Moura (2018) a ICANN (Internet Corporation for Assigned Names and Numbers), desvinculada das estruturas do Poder Judiciário, assume o papel de órgão julgador em casos globais envolvendo liberdade de expressão- função que seria típica do Sistema do Direito.

Trata-se, como se viu, de outro ponto de vista do Direito Constitucional na globalização, evidenciando casos em que as problemáticas deslocam-se do âmbito do Direito Público inclusive, operando nos regimes privados. A síntese desse deslocamento forma um cenário de observação denominado de Constitucionalismo Social (ROCHA; COSTA, 2018a).

Nesse sentido, o próprio Canotilho (2008, p.196) defende a necessidade de uma concepção de Constituição voltada à aprendizagem continua entre os diversos sistemas sociais da sociedade mundial. Nesse sentido: "A complexidade e contingências da sociedade assente em sistemas sociais diferenciados postula, assim, a reescritura permanente das regras constitucionais com base em experiências e em aprendizagens [...]”.

Em síntese, nesse cenário de busca de alternativas aos problemas do Direito Constitucional, oriundo da Sociologia das Constituições, em perspectivas de Constitucionalismo Transnacional (THORNHILL, 2016), Transconstitucionalismo (2008) e Fragmentação Constitucional (2016), sem evidenciar a necessidade de criação de uma estrutura única para a resolução desses problemas, é que surge a proposta da Corte Constitucional Internacional, destacando a importância de se criar um órgão julgador que congregue jurisdição para esses casos, como será demonstrado.

\section{A CORTE CONSTITUCIONAL INTERNACIONAL: ÂMBITO DE APLICAÇÃO E DIFERENÇA EM RELAÇÃO AO ATUAL CENÁRIO DO DIREITO INTERNACIONAL}

Na Tunísia, em um contexto de contestadas eleições repetitivas do então presidente Zine El Abiddine Bem Ali, a proposta de criação de uma Corte Constitucional Internacional

Rev. Brasileira de Teoria Constitucional | e-ISSN: 2525-961X| Goiânia| v. 5 | n. 1 | p. 1 - 20 | Jan/Jun. 2019 
partiu do seu mais forte opositor à época, M. Makouzi, que pleiteou a deposição do regime ditatorial em seu país junto à Organização das Nações Unidas (ONU). (GHAGEM, 2016).

Referida proposta foi aderida por uma série de intelectuais da área, com destaque para Dominique Rousseau, professor de Direito Constitucional da Université Paris 1 PanthéonSorbonne. Em diversos de seus renomados trabalhos, Rousseau passou a destacar a concepção de um Direito Constitucional global existente. (ROUSSEAU, 2015). Ademais, em suas pesquisas defende a criação de mecanismos de efetividade da democracia contínua a nível mundial. (ROUSSEAU, 2015).

A proposta oriunda do político M. Makouzi, da Tunísia, evidenciou o quão frágil é a efetividade da legislação internacional já existente em termos de direitos humanos a nível internacional, demonstrando-se a limitação de órgãos internacionais para o controle de regimes ditatoriais no interior dos diferentes países. Nesse sentido, a ausência de pressupostos democráticos no processo eleitoral da Tunísia ganhou repercussão a nível mundial a partir de sua denúncia junto à ONU, em comunicação realizada por M. Makouzi, cuja consequência imediata foi a adesão de renomados intelectuais ao redor do mundo.

No caso da Tunísia, evidenciou-se que não havia uma instância superior que pudesse oferecer respostas para o problema. A Organização das Nações Unidas (ONU), nesse caso, serviu como lugar de denúncia e divulgação da situação. A criação de uma Corte Constitucional Internacional foi proposta na busca de um mecanismo supranacional de controle que possibilitasse a imposição de métodos democráticos aos governos ao redor do mundo, garantindo a soberania popular a nível mundial. (ATTAR, 2013).

A partir dessa ausência de uma instância superior apta a controlar a aplicabilidade do regime democrático ao redor do mundo, portanto, surgiu a proposta de criação de uma Corte Constitucional Internacional.

O primeiro questionamento que se coloca e relação à referida proposta é no tocante à existência de outras instâncias jurisdicionais internacionais. Nesse sentido: - qual seria a diferença entre a Corte Constitucional Internacional e as outras jurisdições internacionais?

Para responder a esse questionamento, diferenças entre a Corte Constitucional Internacional, a Corte Internacional de Justiça e a Corte Penal Internacional foram destacadas 


\section{A CORTE CONSTITUCIONAL INTERNACIONAL NO ATUAL CONTEXTO DE CONSTITUCIONALISMO SOCIAL: CONTRIBUIÇÕES NA CONSTRUÇÃO DA DEMOCRACIA CONTÍNUA}

na proposta. Inicialmente, no tocante à competência, destacou-se que a Corte Internacional de Justiça possui jurisdição sobre os Estados. A Corte Penal Internacional atua em relação aos crimes mais graves, a exemplo do genocídio, crimes contra a humanidade e crimes de guerra. Já a Corte Constitucional Internacional atuaria em questões relativas ao Estado de Direito e à democracia, para manter a aplicabilidade de seus pressupostos, garantidos a nível mundial pela legislação, no interior dos diferentes países. (GHACEM, 2016).

Outra distinção destacada refere-se ao âmbito de competência das diferentes jurisdições internacionais. Ao passo que a Corte Internacional de Justiça e a Corte Penal Internacional atuam em assuntos internacionais, propõe-se que a Corte Constitucional Internacional atue no âmbito interno dos diferentes Estados. Nesse sentido, a Corte atuaria no controle de constitucionalidade e convencionalidade em relação a práticas constitucionais, legislativas e administrativas praticadas no interior dos países, que estivessem em contrariedade aos direitos civis e políticos garantidos no âmbito internacional. (ATTAR, 2013).

Umas das mais relevantes distinções, destacada por Dominique Rousseau (2015) no âmbito de construção de uma democracia contínua, refere-se ao acesso jurisdicional da Corte Constitucional Internacional. As demais jurisdições constitucionais comparadas acima, a Corte Internacional de Justiça e a Corte Penal Internacional, são de acesso restrito aos Estados.

Avançando nessa questão, propõe-se que a Corte Constitucional Internacional possa ser acessada por pessoas físicas, associações e outros representantes da sociedade civil. (GHACEM, 2016). Assim, a proposta inclui que acesso de ONGs, organizações internacionais e petições coletivas, subscritas por pelo menos 100 (cem) indivíduos sejam aceitas na Corte. (ATTAR, 2013).

Por meio de amplo acesso à justiça, a Corte Constitucional Internacional pode intervir na modificação de leis internas dos diferentes países, bem como anular relevantes processos inconstitucionais, a exemplo de eleições ilegais eivadas de vícios em seus procedimentos democráticos, questão que ganhou maios ênfase na proposta de Markouzi em seu discurso na Assembleia Geral das Nações Unidas. (GHACEM, 2013).

Rev. Brasileira de Teoria Constitucional | e-ISSN: 2525-961X| Goiânia| v. 5 | n. 1 | p. 1 - 20 | Jan/Jun. 2019 
Observa-se quão relevante é a proposta de criação de uma Corte Constitucional Internacional apta a oferecer respostas a questões de extrema relevância no que tange à manutenção dos processos democráticos no interior de diferentes países. Por outro lado, há de se observar o desenvolvimento de alto grau de carência de legitimidade não apenas no âmbito dos Estados, mas também no interior dos regimes de auto-organização do setor privado.

Nesse sentido, mesmo em um ambiente de constante descentralização do Direito Constitucional, caracterizado pela disseminação de fenômenos como as Constituições Transnacionais (THORNHILL, 2016), o Transconstitucionalismo (NEVES, 2008) e a fragmentação constitucional (TEUBNER, 2016), a partir de uma análise sistêmica desse cenário (LUHMANN, 2016), é possível verificar que a criação de uma Corte Constitucional Internacional, nos moldes como apresentada no projeto, pode contribuir para o enfrentamento de determinadas questões a nível global, a exemplo da carência de pressupostos democráticos em processos eleitorais ao redor do mundo, como ocorreu na Tunísia.

Sendo assim, sistemicamente, em termos de Sociologia das Constituições, a Corte Constitucional Internacional atuaria, em contexto global, como fonte jurídica complementar para o enfrentamento das atuais questões em Direito Constitucional.

\section{CONSIDERAÇÕES FINAIS}

Como se viu ao longo do trabalho, o constitucionalismo desenvolveu-se a partir de uma concepção de Constituição como documento único e escrito vinculado a determinado território. Essa perspectiva funda a ordem constitucional nos elementos da Teoria do Estado, a exemplo dos trabalhos de Malberg (1948) na França e Jellinek (2000) na Alemanha.

Tal proposta avançou os debates constitucionais ao longo do século XX, não possuindo relevante discussão, nesse ponto, nas obras de Kelsen (2003) e Schmitt (2007), cujas concepções de Constituição ainda estavam vinculadas ao território de determinado Estado. Observação relevante se faz no tocante à análise do Direito Internacional feita por Kelsen (2003), mas que não altera substancialmente sua perspectiva.

No final do século XX, todavia, com o impulso do fenômeno da globalização, alçando a observação das relações de poder para além dos Estados nacionais, passou-se a observar a necessidade de deslocamento do Direito Constitucional para o plano global. Nesse sentido, os

Rev. Brasileira de Teoria Constitucional | e-ISSN: 2525-961X| Goiânia| v. 5 | n. 1 | p. 1 - 20 | Jan/Jun. 2019 


\section{A CORTE CONSTITUCIONAL INTERNACIONAL NO ATUAL CONTEXTO DE CONSTITUCIONALISMO SOCIAL: CONTRIBUIÇÕES NA CONSTRUÇÃO DA DEMOCRACIA CONTÍNUA}

autores do pluralismo jurídico, a exemplo de Bermann (2013), Shaffer (2012) e Tamanaha (2008) descreveram sociologicamente o processo de transnacionalização do constitucionalismo.

Em tal transição, como se viu, é relevante a mudança de posicionamento de José Joaquim Gomes Canotilho. O constitucionalista português sai de uma perspectiva voltada à consideração de uma Constituição dirigente (CANOTILHO, 1982), enquanto documento único e escrito a ditar os objetivos a serem conquistados por determinado Estado, etapas do dirigismo constitucional, para uma análise das relações entre os direitos constitucionais dos diferentes estados da União Europeia, formando o que denomina de interconstitucionalidade (CANOTILHO, 2008).

Ademais, como observado, fez-se relevante a transição proposta no modelo de Direito Constitucional dos Estados Unidos por Bruce Ackermann (2002), defendendo a necessidade do abandono de um modelo provincialista, em busca de uma abertura ao fenômeno da globalização.

Como ponto central nessa transição, todavia, observou-se que os estudos em Sociologia das Constituições passaram a se dedicar às observações das relações entre Direito e Política na sociedade mundial descrita por Luhmann (2016).

Partindo da concepção luhmanniana de Constituição, como se viu, Chris Thornhill (2016) observa a existência de um núcleo comum positivado em matéria de direitos humanos em Constituições de diferentes países que tiveram processos constituintes realizados após a Segunda Guerra Mundial. Para Thornhill (2016), há, portanto, um verdadeiro Constitucionalismo Transnacional, que perpassa as fronteiras dos Estados nacionais em termos de garantias de direitos.

Embasando essa afirmação, viu-se a observação de Marcelo Neves (2003), mencionando que os problemas constitucionais atuais possuem natureza global, a exemplo de casos como o terrorismo, o direito ambiental e a criminalidade transnacional. Pode-se adicionar, ainda, atualmente, em complementação, a articulação internacional para o combate à lavagem de dinheiro (COSTA; ROCHA, 2018).

Em síntese, a existência de problemas de natureza global incentiva a utilização desse Constitucionalismo Transnacional existente na resolução de casos enfrentados no âmbito dos diferentes Estados (THORNHILL, 2016). Aproximando-se disso, Marcelo Neves (2003), 
como se viu, defende a articulação de uma conversação constitucional entre cortes de diferentes níveis para a solução dessas situações.

Avançando nessa questão, observou-se a afirmação de Teubner (2016), demonstrando que as funções típicas do Direito Constitucional, mormente a regulação do exercício do poder, atualmente saem do âmbito público. Há organizações pertencentes a outros sistemas sociais exercendo atividades antes voltadas à dimensão do constitucionalismo. Nesse sentido, o trabalho de Moura (2018) evidencia o papel da ICANN (Internet Corporation for Assigned Names and Numbers) na decisão de conflitos envolvendo liberdade de expressão no âmbito global da internet. Está a se observar, portanto, um órgão alheio ao Direito exercendo funções típicas do Poder Judiciário, discutindo, inclusive, acerca de direitos como a liberdade de expressão.

Em suma, nesse contexto de avanço do Direito Constitucional para o âmbito global, tendo como característica principal a descentralização, o deslocamento de decisões proferidas por órgãos jurisdicionais únicos e baseados em legislação estritamente nacional para construções de diálogos entre cortes (NEVES, 2003) a partir da observação de Constituições Transnacionais (THORNHILL, 2016), além da evidência de atores privados assumindo funções constitucionais (TEUBNER, 2016) é que surge a proposta de criação de uma Corte Constitucional Internacional.

Partindo da denúncia acerca da ausência de mecanismos de controle de processos eleitorais em diferentes países, com destaque para a Tunísia, local em que o opositor a um regime que se perpetuava no poder trouxe à tona essa questão, o problema levantado nesta pesquisa, seguindo o âmbito da explanação realizada na Organização das Nações Unidas (ONU), M. Makouzi, referiu-se à ausência de mecanismos aptos a darem efetividade à legislação internacional em direitos humanos no tocante ao controle de processos eleitorais ao redor do mundo.

Nesse âmbito, foram destacados como temas centrais a proposta de criação de uma Corte Constitucional Internacional e o atual ambiente do constitucionalismo em que essa proposta estaria inserida, evidenciando os recentes estudos em Sociologia das Constituições, que demonstram a descentralização crescente do Direito Constitucional.

Como objetivo, portanto, buscou-se evidenciar uma distinção entre o projeto de criação de uma Corte Constitucional Internacional e os atuais estudos acerca do constitucionalismo na globalização.

Rev. Brasileira de Teoria Constitucional | e-ISSN: 2525-961X| Goiânia| v. 5 | n. 1 | p. 1 - 20 | Jan/Jun. 2019 


\section{A CORTE CONSTITUCIONAL INTERNACIONAL NO ATUAL CONTEXTO DE CONSTITUCIONALISMO SOCIAL: CONTRIBUIÇÕES NA CONSTRUÇÃO DA DEMOCRACIA CONTÍNUA}

Nesse sentido, como se viu, a competência da Corte Constitucional Internacional difere em muito das demais jurisdições existentes a nível internacional. A Corte Internacional de Justiça, por exemplo, possui jurisdição sobre os Estados. A corte Penal Internacional, por sua vez, direciona a atuação em relação a crimes de natureza mais grave, tais como genocídio, crimes contra a humanidade e crimes de guerra.

A proposta da Corte Constitucional Internacional é a de atuar em problemas tocantes ao Estado de Direito e à democracia, a exemplo do controle de processos eleitorais em países como a Tunísia. Nesse sentido, a atuação recomendaria a aplicabilidade de pressupostos democráticos do Estado de Direito, mantando suas garantias a nível mundial, nas legislações de diferentes países. (GHACEM, 2016).

Outra relevante distinção, consoante demonstrado, é no tocante ao âmbito de competência das diferentes jurisdições internacionais. Nesse sentido, viu-se que a Corte Internacional de Justiça e a Corte Penal Internacional atuam em assuntos internacionais. $\mathrm{Na}$ proposta, a Corte Constitucional Internacional atuaria no controle de constitucionalidade e convencionalidade em relação a práticas constitucionais, legislativas e administrativas praticadas em diferentes países, verificando eventuais violações aos direitos civis e políticos garantidos no âmbito internacional. (ATTAR, 2013).

Nesse sentido, aspecto de destaque na distinção da Corte Constitucional Internacional em relação às demais jurisdições internacionais é no tocante ao acesso à justiça. A Corte Internacional de Justiça e a Corte Penal Internacional possuem acesso restrito aos estados. Por sua vez, a Corte Constitucional Internacional propõe o acesso à sua jurisdição por pessoas físicas, associações e outros representantes da sociedade civil. (GHACEM, 2016). Assim, petições coletivas, subscritas por pelo menos 100 (cem) indivíduos, são aceitas na Corte. Ao mesmo passo que ONGs e demais organizações internacionais também possuem acesso a ela. (ATTAR, 2013).

Tal amplitude no direito de acesso permite a construção do que Dominique Rousseau (2015) denomina de democracia contínua. Com essa proposta, em amplo acesso à justiça, a Corte Constitucional Internacional pretende intervir na legislação de diferentes países, podendo anular procedimentos inconstitucionais, a exemplo do problema eleitoral em que a

Rev. Brasileira de Teoria Constitucional | e-ISSN: 2525-961X| Goiânia| v. 5 | n. 1 | p. 1 - 20 | Jan/Jun. 2019 
Tunísia esteve envolvida, denunciada pelo político Markouzi em seu discurso na Assembleia Geral das Nações Unidas. (GHACEM, 2013).

Em aportes finais, conclui-se, portanto, que apesar das relevantes evoluções no âmbito do Direito Constitucional para a solução de problemas de natureza global, a exemplo dos estudos acerca das Constituições Transnacionais (THORNHILL, 2016) e do Transconstitucionalismo (NEVES, 2008), demonstra-se necessária e complementar a proposta de criação de uma Corte Constitucional Internacional, com o objetivo de oferecer respostas a questões conectadas à manutenção do Estado de Direito e da democracia ao redor do mundo.

Nesse sentido, ocupando função que não é prioridade no âmbito da Sociologia das Constituições, a Corte Constitucional Internacional, em uma observação sociológicosistêmica (LUHMANN, 2016) seria capaz de atuar na manutenção dos processos democráticos no interior de diferentes países, contribuindo para a resolução de problemas constitucionais a nível global. Sendo assim, resolveria os problemas atuais no tocante ao alto grau de carência de legitimidade no âmbito dos Estados, mas também e dos regimes de autoorganização do setor privado. Serviria, no atual contexto de Constitucionalismo Social (ROCHA; COSTA, 2018), como fonte complementar para o tratamento de problemas relacionados ao Direito Constitucional na globalização.

\section{REFERÊNCIAS}

ACKERMAN, Bruce. A ascensão do constitucionalismo mundial. In: SOUZA NETO, C. P.; SARMENTO, D. (orgs.). A constituição do direito: fundamentos teóricos e aplicações específicas. Rio de Janeiro: Lumen Juris, 2007, p. 89-111.

ATTAR, Oriane Ben. « Note d'actualité concernant la proposition du Président de la République tunisienne Mohamed Moncef Marzouki lors du débat général le 26 octobre 2013 devant l'Assemblée générale des Nations Unies de créer une Cour constitutionnelle internationale », Civitas Europa 2013/2 (N³1), p. 287. Disponível em: < https://www.cairn.info/revue-civitas-europa-2013-2-page-285.htm>. Acesso em 19 out. 2018.

BERMAN, Paul Schiff. Global Legal Pluralism. A Jurisprudence of Law Beyond Borders. Cambridge: Cambridge University Press, 2013. 


\section{A CORTE CONSTITUCIONAL INTERNACIONAL NO ATUAL CONTEXTO DE CONSTITUCIONALISMO SOCIAL: CONTRIBUIÇÕES NA CONSTRUÇÃO DA DEMOCRACIA \\ CONTÍNUA}

CANOTILHO, J. J. Gomes. 'Brancosos' e interconstitucionalidade: itinerários dos discursos sobre a historicidade constitucional. 2. ed. Coimbra: Almedina, 2008.

Constituição dirigente e vinculação do legislador: contributo para a compreensão das normas constitucionais programáticas. Coimbra: Coimbra, 1982.

COSTA, Bernardo Leandro Carvalho; ROCHA, Leonel Severo. Governança global no combate à lavagem de dinheiro: observações sobre a evolução das Constituições

Transnacionais no Tribunal Regional Federal da $4^{a}$ região ao longo da Operação Lava Jato. In: IX Congresso Nacional da Associação Brasileira de Pesquisadores em Sociologia do Direito, 2018, São Paulo. Anais do IX Congresso Nacional da Associação Brasileira de Pesquisadores em Sociologia do Direito. São Paulo: Abrasd, 2018. v. único. p. 139-149.

\section{DECLARAÇÃO DOS DIREITOS DO HOMEM E DO CIDADÃO. MINISTÉRIO}

PÚPLICO FEDERAL. Disponível em: < http://pfdc.pgr.mpf.mp.br/atuacao-e-conteudos-deapoio/legislacao/direitos-humanos/declar_dir_homem_cidadao.pdf>. Acesso em: 04 abr. 2019.

FEBBRAJO, Alberto. Sociologia do constitucionalismo. Curitib : Juruá, 2016.

GHACHEM, Asma. Plaidoyer pour une idée tunisienne: l'institution d'une Cour constitutionnelle internationale. International Studies on Law and Education. 24 set-dez, p.43, 2016. Disponível em: 〈http://www.hottopos.com/isle24/43-50Grachen.pdf>. Acesso em 20 out. 2018.

LUHMANN, Niklas. O Direito da sociedade. São Paulo: Saraiva, 2016.

MOURA, A. A. L.. 'Lex Digitalis' e flexibilidade do Direito. In: Sociology Of Law 2018 - O Direito entre o caos e a desconstrução, 2019, Canoas/RS. Anais Sociology of Law 2018 [recurso eletrônico]: o direito entre o caos e a desconstrução. Canoas: Unilassale, 2018. p. $88-98$.

NEVES, Marcelo. Transconstitucionalismo. São Paulo: Martins Fontes, 2009.

ROCHA, Leonel Severo; COSTA, Bernardo Leandro Carvalho. Constitucionalismo social: Constituição na globalização. Curitiba: Appris, 2018. 
ROCHA, Leonel Severo. Epistemologia do Direito: revisitando as três matrizes jurídicas.

Revista de Estudos Constitucionais, Hermenêutica e Teoria do Direito (RECHTD), São

Leopoldo, ano 5, v 2, julho-dezembro 2013. p. 141-149. Disponível em: <

http://revistas.unisinos.br/index.php/RECHTD/article/view/rechtd.2013.52.06/3934>. Acesso em: 03 abr. 2019.

ROUSSEAU, Dominique. «Le droit constitutionnel peut-il être global ? ».

Communication orale au colloque de Rabat des 16 et 17 juin 2015.

La démocratie continue. Paris-Brussel, Bruylant/LGDJ, 2015.

SHAFFER, Gregory. Transnational Legal Process and State Change: Opportunities and Constrainst. Law e Social Inquiry, v.37, I.2, pages 229-264, Spring, 2012.

TAMANAHA, Brian Z. Undestanding Legal Pluralism: Past to Present, Local to Global. Sydney Law Review, pp. 375-411. 2008.

TEUBNER, Günther. A bukowina global sobre a emergência de um pluralismo jurídico internacional. Impulso: Revista de Ciências Sociais e Humanas, [S.1.], v. 14, p. 10, 2003.

Fragmentos Constitucionais: constitucionalismo social na globalização. São Paulo: Saraiva, 2016.

THORNHILL, Chris. A sociology of Constitutions: Constitutions and State Legitimacy in Historical-Sociological Perspective. London: Cambrigde, 2011.

A sociology of Transnational Constitutions: Social foundations of the post-national legal structure. London: Cambrigde, 2016.

Rev. Brasileira de Teoria Constitucional | e-ISSN: 2525-961X| Goiânia| v. 5 | n. 1 | p. 1 - 20 | Jan/Jun. 2019 